\title{
Recognising and responding to the maltreatment of disabled children: A children's rights approach
}

\author{
J. Hernon ${ }^{1}$, M. Brandon ${ }^{2}$, J. Cossar, ${ }^{3}$ and T. Shakespeare ${ }^{4}$
}

\begin{abstract}
Research has established that disabled young people are at greater risk of experiencing all forms of maltreatment, especially neglect (Jones et al, 2012). Despite increasing awareness of their heightened vulnerability, the maltreatment of disabled children remains under-recognised and is under-reported. Disabled children have the same rights as all children to be protected from maltreatment; to have their concerns listened to; to participate fully in decisions made about them; and to receive help to recover from maltreatment. In this paper Cossar et al's (2013) framework for understanding the processes of recognition, telling and receiving help following maltreatment from the child's perspective, is applied to disabled children. The particular barriers that disabled children and those working with them face in recognising and responding to maltreatment are analysed by reviewing what is known about child protection practice with disabled children, mainly in the UK. Suggestions are made about how practice with disabled children could be improved.
\end{abstract}

Keywords: disabled children; children's rights; recognition; maltreatment

1. PhD Researcher

2. Professor of Social Work

3. Senior Lecturer

4. Senior Lecturer at Norwich Medical School, University of East Anglia

Address for correspondence: Jane Hernon, School of Social Work, University of East Anglia, Norwich, NR47TJ, UK.J.Hernon@uea.ac.uk 


\section{Introduction}

Child maltreatment and its associated consequences are a major global public health concern, which has been the subject of international attention in recent decades. This has been prompted, not least through the introduction of the UN Convention on the Rights of the Child (UNCRC, 1989). This sets out states' responsibilities to respect and ensure children's rights to protection (Article 19); to express their views and to have these views taken seriously (Article 12); to be provided with support, including to aid recovery from abuse (Article 36). These core rights are seen as crucially interconnected within a children's rights approach to maltreatment (UN Committee on the Rights of the Child, 2003), and have guided much recent child welfare policy development, especially in high-income countries (Reading et al, 2009).

All children, including disabled children, have the same rights (Article 2). The United Nations Convention on the Rights of Persons with Disabilities (UNCRPD, 2006) reinforces states' responsibilities to provide for disabled children's additional needs in sustaining their equal rights, including the right to express their views (Article 7) and that of protection (Article 16). However the overlap between disability and maltreatment has generally received much less attention Mikton, Maguire, $\&$ Shakespeare, 2014). This paper discusses the evidence linking disability with maltreatment, before reviewing what is known about recognising and responding to maltreatment involving disabled children. It then considers how practice might be improved, using Cossar et al's (2013) framework for understanding recognition, telling and help, based on children's perspectives about maltreatment.

\section{Disabled children and maltreatment}

Disabled children have long been considered at greater risk of violence and maltreatment (Kelly, 1992; Sobsey, 1994; Westcott and Jones, 1999). A substantial body of evidence now exists to support this assertion. While estimates vary, a recent meta-analysis confirmed Sullivan and Knutson's (2000) earlier work, finding violence and maltreatment to be 3 to 4 times more common among disabled children, with emotional abuse and neglect most prevalent (Jones et al, 2012). Several studies indicate that disabled children's risk of maltreatment varies according to impairment type, with having a mental or intellectual disability, communication impairment or behavioural difficulty being more strongly associated with maltreatment (Sullivan and Knutson, 2000; Spencer et al, 2005; Jones et al, 2012).

Despite persistent evidence linking disability with maltreatment, the underlying causes for this association remain poorly understood. Robust, well-designed studies on this topic remain scarce, with very few population-based studies, and only a 
handful of studies adequately controlling for possible confounding factors, such as birth-weight and socio-economic status (Jones et al, 2012). Wide variation in how disability and maltreatment are defined also makes comparison across different studies difficult, further contributing to a lack of clarity regarding prevalence rates (Jones et al, 2012). Current studies also shed little light on the important question of the extent to which disability can be a consequence of, rather than a risk factor for maltreatment (Jones et al, 2012), and much literature gives scant consideration to theoretical perspectives (Leeb et al, 2012).

Nevertheless, a number of possible explanations for disabled children's increased risk of maltreatment have been proposed. Early theories suggested disabled children's additional difficulties and support needs potentially triggered maltreatment due to increased parental stress (Ammerman, 1991). Empirical evidence has provided little support for this explanation, however, since severity of disability does not necessary correlate with increased parental stress or risk of maltreatment (Benedict et al, 1992; Verdugo et al 1995). Conversely, Spencer et al 2005, suggest the higher numbers of children with learning difficulties or behavioural problems they found who were the subject of a child protection plan, was due partly to these conditions more often occurring as a direct consequence of neglectful parenting.

More recent accounts, drawing on transactional-ecological understandings of child development and maltreatment (Cicchetti et al, 2000), explain the association between disability and maltreatment as arising from complex interactions between vulnerability factors in the child, their carers and the wider environment. At an individual level the quality of the attachment relationship between a child and his or her carers is seen as promoting or impeding the potential for both development and maltreatment. Howe (2006) argues it is this factor, rather than the presence of disability per se, that accounts for increased maltreatment rates among disabled children. This assertion is supported by a meta-analysis finding lower levels of secure attachments and slightly more disorganised attachments among disabled children (van IJzendoorn et al, 1992).

Transactional-ecological perspectives may also help explain evidence of interrelationships between disability, maltreatment and other forms of disadvantage. For example, numerous studies have identified increased incidence of both disability and maltreatment among children from lower socio-economic backgrounds (e.g. Blackburn et al, 2010; Sidebotham et al, 2002). Carers of disabled children are also more likely to experience social isolation and financial problems, due to higher costs and reduced employment opportunities (Leeb et al, 2012), factors that have been shown to cumulatively affect maltreatment risk (Stith et al, 2009; MacKenzie et al, 2011).

In addition, interactions between disability and other socio-demographic variables may help account for the different maltreatment patterns noted among disabled children (Stalker and McArthur, 2012). For example, most evidence put disabled boys at even higher risk of maltreatment than non-disabled boys (Kvam, 2000), in one study making up 70.3\% of maltreated disabled children (Sullivan and Knutson, 
2000). Herschkowitz et al (2007) also found disabled boys were significantly more likely than disabled girls to experience physical abuse, but less likely to be sexually abused. However, Briggs (2006) found disabled boys were equally likely to experience sexual abuse, but less likely to report it.

Evidence regarding how other factors may influence disabled children's risk of maltreatment is less clear. For example, while Sullivan and Knutson (2000) found maltreatment of disabled children began at earlier ages, Herschkowitz et al (2007) found no such differences. Similarly, while cultural and religious attitudes towards disability have been shown to affect disabled children's experiences and life chances (Danseco, 1997; United Nations, 2006), most research indicates no differences in maltreatment and disability rates between different races (Gourdine, 2013). However, one study found maltreatment rates were significantly higher among white children than Hispanic children and those from other ethnic minorities (Jaudes and MackeyBilaver, 2008).

Negative prevailing social attitudes and discrimination towards disabled people, highlighted by social models of disability (Westcott and Jones, 1999), may help explain other evidence suggesting maltreatment involving disabled children tends to be more severe (Sullivan and Knuston, 2000; Kvam, 2004), is often more violent (Akbas et al, 2009), and is more likely to involve multiple forms and recurrent episodes of abuse than that involving non-disabled children (Sullivan and Knutson, 2000). However, while it seems reasonable to conclude from the evidence reviewed above, that disability represents an important risk factor for maltreatment, this association and its underlying causes are complex and variable (Stalker and McArthur, 2012; Leeb et al, 2012).

\section{Recognising and Responding to the maltreatment of disabled children}

Given that disabled children are at greater risk of maltreatment, recognising and responding to maltreatment involving disabled children should be a priority. Yet recent reviews identified several areas of concern in relation to child protection practice with disabled children in the UK (Ofsted, 2012; Taylor et al, 2014). Stalker et al's (2010) policy review concluded that disabled children were 'almost invisible' within mainstream child protection policies in the 4 UK countries, and the Munro Review of Child Protection in England and Wales (HM, 2011) made no reference to disabled children's increased risk of maltreatment, illustrating an underlying trend for childhood disability to be regarded as a separate policy issue (Stalker, 2012).

The remainder of this paper applies Cossar et al's (2013) framework for understanding recognition, telling and help from children's perspectives about maltreatment, to what is known about recognising and responding to maltreatment 
involving disabled children. Suggestions are made about how practice with disabled children might be improved and their rights upheld. It is important to acknowledge, however, that disabled children's heterogeneity (Watson, 2012) means that their experiences of maltreatment and seeking help are likely to be as complex and varied as those described by non-disabled children. Research regarding disabled children's own perspectives about maltreatment and child protection is also lacking, and represents an important direction for future research (Stalker and McArthur, 2012).

\section{Approach to literature search}

A narrative rather than systematic approach was taken to identifying relevant literature, and a range of search strategies was used. This reflects the need to include grey (unpublished) literature given its relevance to practice, and the dearth of empirical research on this topic (Stalker and McArthur, 2012). The findings of practice inspections (Ofsted, 2012), policy reviews (NSPCC 2003; Stalker et al 2010) and reports of empirical studies (Brandon et al, 2011; Taylor et al 2014) are therefore discussed alongside research published in peer-reviewed academic journals.

Journal articles were retrieved by entering key search terms, (disab*, child welfare, protect*, maltreatment, abuse) into Metalib, (including MEDLINE and Applied Social Sciences Index (ASSIA) databases). Unpublished literature was retrieved by entering these search terms into Google and Google Scholar. Further literature was obtained through searching the bibliographies of relevant articles and reports, and via key informants in research and practice. While the review focuses on the UK, the barriers disabled children and practitioners experience recognising, telling and receiving help with maltreatment seem likely to be similar in other high income countries (Lightfoot and La Liberte, 2013; Kvam, 2004), despite variations across child welfare systems (Thoburn, 2013). Therefore international literature is referred to where relevant.

The majority of the empirical studies examined employ qualitative methods, with findings based on interviews and focus groups with practitioners and managers working with disabled children in child protection. The quality of evidence varies, for example studies often relied only on recall and self-report. Qualitative studies lack generalisability due to their small sample sizes. As already stated, disabled children's perspectives on maltreatment and child protection remain largely unknown (Stalker and McArthur, 2012). Quantitative surveys, seeking to understand disabled children's presence within child welfare processes, are limited by wide variation in how disability and maltreatment are defined (Lightfoot and La Liberte, 2011) and by poor recording practices (Cooke and Standen, 2002). Despite these limitations, the studies reviewed highlight a number of consistent themes concerning child protection practice with disabled children (Osborne, 2013). 


\section{Recognising and responding to maltreatment: The child's perspective}

From a children's rights perspective, understanding what children say helps them is essential for improving their access to support and protection, and for remaining focused on outcomes for the child (HM, 2011). Cossar et al's (2013) research explored how the processes of recognising and telling about maltreatment and receiving help are experienced from the child's perspective. Their study consisted of a structured literature review, content analysis of an online peer support website, in-depth qualitative interviews with thirty young people aged 11-20 at risk of maltreatment, and six focus groups with young people, parents, and practitioners. Findings were used to develop a conceptual framework to help practitioners understand both the barriers children face in recognising maltreatment and talking about it, and also how the responses children receive can promote or hinder their capacity to tell someone about maltreatment and access help.

Figure 1

Framework for Recognition, Telling and Help, Cossar et al (2013)

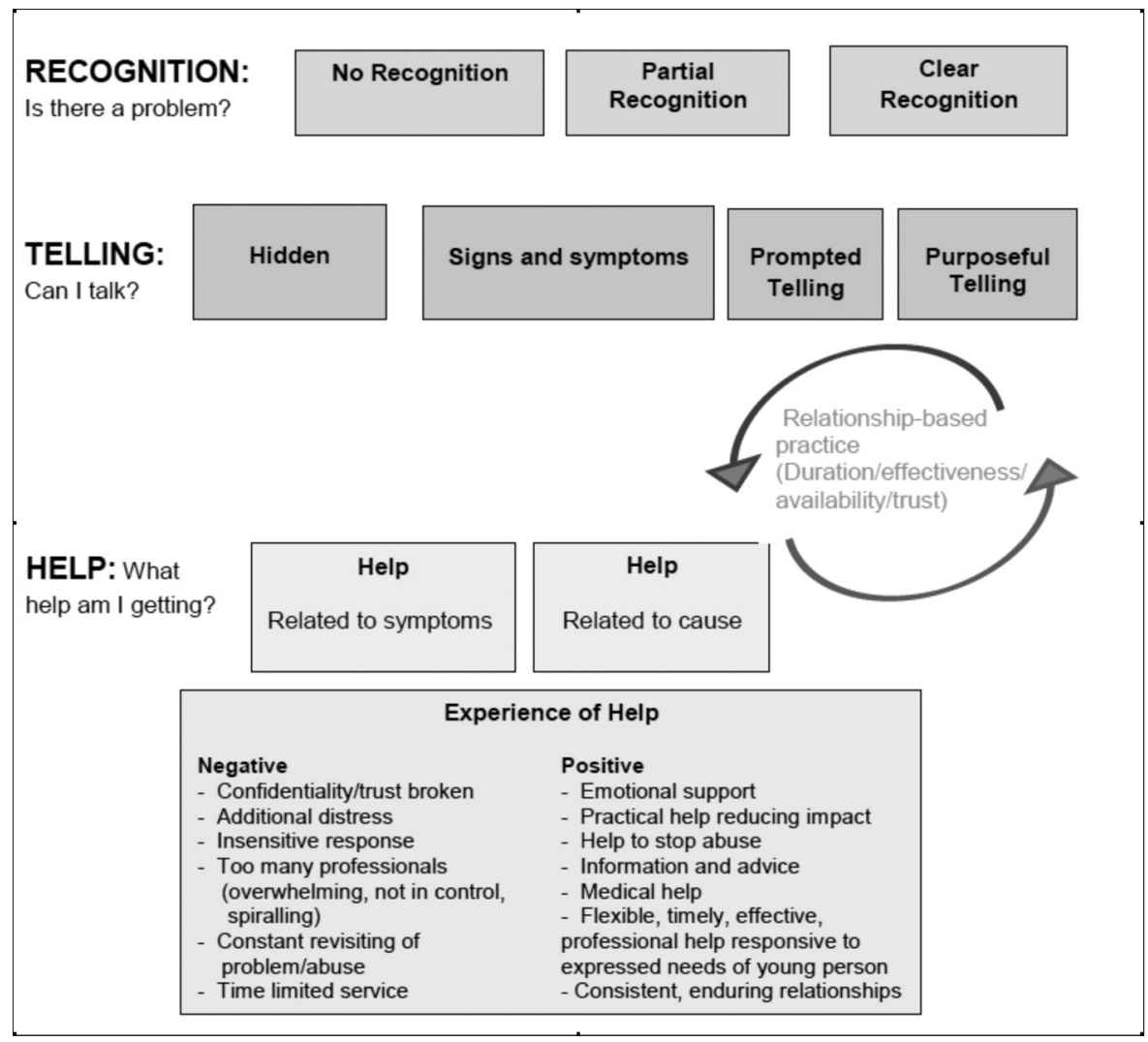


Cossar et al's (2013) framework seems particularly relevant for disabled children given they are at greater risk of maltreatment (Jones et al, 2012) and that maltreatment involving disabled children is under-recognised and under-reported (Cooke and Standen, 2002; Ofsted, 2012). Contributing to this under reporting is evidence that disabled children themselves are less likely to report maltreatment (Herschkowitz et al, 2007). Practitioners may also tend to disregard disabled children's accounts (Kvam, 2004) or wrongly attribute signs of maltreatment to children's impairments (Brandon et al, 2011), contributing to maltreatment involving disabled children remaining undetected.

\section{Recognition}

Cossar et al's (2013) research identified recognition of maltreatment along a spectrum, from 'no recognition' to 'clear recognition', with many children describing their understanding as beginning with an emotional awareness that things were not right ('partial recognition'). Recognition was often gradual, and it was not the case that children first recognised maltreatment, then told about it, and then received help. Sometimes children recognised maltreatment only after receiving help. Barriers to recognising maltreatment included children feeling they deserved it; difficulty acknowledging adults, particularly parents as abusive (especially where relationships were sometimes good); confusion about boundaries between discipline and physical abuse and differences between appropriate and inappropriate touching in relation to sexual abuse (Cossar et al, 2013). Children found recognising emotional abuse or neglect especially difficult (Cossar et al, 2013).

Research with disabled children suggests that these barriers may be especially challenging for some disabled children. For example, many disabled young people in Connors and Stalker's (2007) research had experienced others making them feel different or of lesser value because of their impairments, and over half had experienced bullying. In the context of maltreatment, the negative messages some disabled children may have internalised about their impairments could make it more likely that they would blame themselves. Disabled children's access to social networks and friendships may be restricted as a result of attending special schools considerable distances from their homes, mobility difficulties or parents' protectiveness towards learning disabled children (Watson et a, 1999; Kelly, 2005). Reduced opportunities to visit or spend time with friends, limits disabled children's possibilities for comparing their situations and families with those of others, which Cossar et al (2013) identified as central to children's recognition of maltreatment. Differentiating between appropriate and inappropriate touch, can be more challenging for disabled children who have always relied on others for intimate care; who may have become accustomed to allowing others unrestricted access to their bodies; or may be physically less able to stop abuse from happening (Murray 
and Osborne, 2009). Children's impairments can themselves also act as a barrier to recognising maltreatment. For example, cognitive impairments or autism can affect children's emotional development and ability to understand appropriate boundaries and to recognise others' behaviour as abusive. Deaf children and children with communication difficulties may also lack access to information about, and consequently understanding of, maltreatment (Murray and Osborne, 2009). All these factors contribute to disabled children being less able to recognise maltreatment, and potentially to them being targeted by perpetrators (Westcott and Jones, 1999).

\section{Telling}

Cossar et al (2013) identified a similar spectrum related to telling, ranging from maltreatment remaining 'hidden', being signalled by changes in children's behaviour or presentation ('signs and symptoms'), through to children's 'prompted telling' (through another person persisting in enquiring about their welfare) or 'purposeful telling' about maltreatment (the child sought someone out to tell about maltreatment). The first two categories, 'hidden' where the child may be actively denying maltreatment, or is showing 'signs and symptoms' of maltreatment, do not require that the child him or herself recognises the maltreatment. Even where children recognised what was happening was wrong they experienced many barriers to telling. These included: fear of consequences or of not being believed; struggling to find or express the right words; feeling ashamed or embarrassed; worrying about the impact on family relationships; or being threatened by their abuser (Cossar et al, 2013).

Many of the factors contributing to disabled children's difficulties recognising maltreatment may also affect their capacity to tell someone about their experiences. For example, the social isolation of some disabled children can mean they are less likely to have a trusted friend or adult to talk to about their problems. Recent research studies in Australia and Norway highlight how this is particularly true of children with complex communication impairments (Raghavendra et al, 2013), and learning difficulties (Ytterus, 2012). In addition, children with these impairments may be less likely to have access to someone with the necessary skills to explain to them about maltreatment, or lack access to appropriate vocabulary to understand and communicate about these issues (Murray and Osborne, 2009). Disclosing maltreatment can also be more risky for children who may be physically dependent on their abuser (NSPCC, 2003).

Disabled children have the same rights as all children to express their concerns, whether directly or through their behaviour, and for those concerns to be taken seriously. However, practitioners' report generally feeling ill-equipped to facilitate disclosures of maltreatment by disabled children, particularly children with communication and learning impairments (Cooke and Standen, 2002; Taylor et 
al, 2014). This factor may contribute to practitioners tending to disbelieve disabled children's accounts. For example Kvam's (2004) retrospective study of 302 deaf adults in Norway, found $10 \%$ of those who reported being abused as children, were not believed. In addition, practitioners report particular difficulties interpreting changes in disabled children's behaviour that might indicate maltreatment (Orelove et al, 2000; Cooke and Standen, 2002). This may lead practitioners to mis-attribute signs of maltreatment to children's impairments. For example, an analysis of practice in a sample of serious case reviews identified instances of bruising being implausibly accepted as related to children's impairments, and of practitioners failing to adequately scrutinise alternative explanations. A tendency to 'see the disability, not the child' was also identified as contributing to maltreatment involving disabled children being missed (Brandon et al, 2011). While there are occasionally instances where maltreatment is wrongly suspected when the issue is the impairment, for example fractures in osteogenesis imperfecta (Hibbard and Desch, 2007), it is worrying that the fear of getting it wrong can deter some practitioners from acting on concerns for disabled children (Taylor et al, 2014).

Ofsted's (2012) inspection of English practice identified 'too many' cases where social workers had failed to identify child protection concerns for disabled children already receiving support via children in need services. Other evidence suggests higher child protection referral thresholds are sometimes applied to disabled children. For example practitioners in Taylor et al's (2014) study reported that 'a wee bit of neglect' was more likely to be tolerated in cases involving disabled children, because practitioners over-empathised with parents due to the additional stress of caring for a disabled child. Brandon et al's (2011) analysis of serious case reviews identified similar instances of agencies accepting a different or lower standard of care for disabled children than their non-disabled peers. Cooke and Standen's (2002) survey study also found that maltreatment involving disabled children was less likely to be recognised until the signs and symptoms were severe.

Recent inspection reports and research with practitioners found however, that a wide range of professionals identify and appropriately refer concerns for disabled children (Ofsted, 2012; Taylor et al, 2014). Taylor et al's (2014) research also found direct disclosure by disabled children triggered the most child protection referrals in the Scottish cases they examined, leading them to conclude that the numbers of disabled children who lack the capacity to recognise and communicate about maltreatment may be overstated by practitioners. A number of research studies with disabled children have emphasised their capacity for agency (Watson et al, 1999; Connors and Stalker, 2003), including research with young people with complex communication impairments (Wickenden, 2011) and learning difficulties (Kelly, 2005). All the above examples underline the increased onus on practitioners to develop the communication skills and child protection knowledge required to understand and listen to disabled children, rather than just relying on children's capacity to report maltreatment (Brandon et al, 2011). 


\section{Helping}

Practitioners' availability and reliability was considered important in determining the quality of help received by young people in Cossar et al's (2013) study. Help provided to address maltreatment symptoms, indicated by children's behaviour or distress, included mental health services or help with anger management. Such help was often provided without the maltreatment underlying these problems being recognised or addressed, for example via child protection enquiries (Cossar et al, 2013). Children who experienced child protection processes valued access to clear information and being listened to and involved in decision-making, but disliked having too many professionals involved or being interrogated as a source of evidence (Cossar et al, 2011).

Disabled children have the same rights to access these helping processes as non-disabled children. Again, evidence suggests that in practice disabled children's access to these services may not be the same. For example, Cooke and Standen (2002) found that disabled children were significantly less likely to have a child protection plan following child protection conferences than were non-disabled children (54\% vs $82 \%$ ). Disabled children made up only $3.8 \%$ of children receiving support via child protection plans in England and Wales in 2011 (DfE, 2011), despite approximately $7 \%$ of children being disabled (Ofsted, 2012). Poor recording practices may contribute, however, to disabled children's apparent under-representation within child protection systems (Cooke and Standen, 2002).

Disabled children's experience within child protection processes often differs from that of non-disabled children in other ways. For example, successive reviews have found that disabled children are less likely to be spoken to during child protection enquiries (Cooke and Standen, 2002; NSPCC, 2003; Ofsted, 2012). Taylor et al's (2014) research found that practitioners often struggle to adapt child protection procedures to meet disabled children's needs. Frontline practitioners often lack necessary skills for communicating with disabled children, however arrangements to involve professionals with appropriate expertise are ad hoc. Practitioners' difficulties engaging with disabled children can lead to an over-reliance on parents' views, meaning children's perspectives can be overlooked (Brandon et al, 2011). Other research highlights that a medical or impairment-centred approach predominates in child protection enquiries concerning disabled children. For example Cooke and Standen (2002) found disabled children were more likely to undergo medical examination and/or treatment than were non-disabled children. Manders and Stoneman (2009) study also found US child protection workers were more likely to view disabled children in case vignettes as having characteristics that had contributed to the maltreatment.

Ofsted's (2012) recent inspection report identified examples of disabled children's views being successfully included in assessments. Practitioners in Taylor et al's (2014) study similarly identified examples of child protection processes being 
successfully adapted to obtain disabled children's accounts. However, even in these cases, disabled children's evidence tended to be regarded as unreliable by police or prosecutors, and none of the cases examined by Taylor et al (2014) had resulted in criminal proceedings. While adequate steps had reportedly been taken to protect these children, a lack of access to criminal justice is disempowering, and may affect children's willingness to report future concerns and access help (Cossar et al, 2013).

Disabled children have an equal right to help with recovering from maltreatment, yet evidence suggests that maltreated disabled children's access to services to specifically meet these needs is unequal. Cooke and Standen's (2002) survey, for example found that disabled children were less likely to be referred for therapeutic support following substantiated maltreatment. Although Ofsted (2012) found that most disabled children with child protection plans made good progress, these plans lacked a focus on outcomes for the child, and advocacy services were rarely used to understand disabled children's own perspectives of their support needs. In addition, Taylor et al (2014) highlighted a shortage of suitably trained foster-carers as adversely affecting child protection practice with disabled children, which in one case had delayed a disabled child being removed from a risky family situation.

\section{Discussion}

In this paper Cossar et al's (2013) framework for understanding the processes of recognition, telling and accessing help following maltreatment from the child's perspective was applied to disabled children. The particular barriers that disabled children and those working with them may face in recognising and responding to maltreatment were analysed by reviewing the available evidence. Cossar et al's (2013) framework could itself be used to help address some of the issues raised, for example to train practitioners working with disabled children to remain alert to the possible meaning of changes in their behaviour, and whether or not these might indicate maltreatment.

This review identified some examples of effective child protection practice with disabled children. Understanding from these examples could be usefully applied to improve practice more widely. For example Taylor et al (2014) identified interagency working, and pooling of skills and knowledge between practitioners as strategies that improved practitioner confidence in their ability to recognise and communicate with disabled children about possible maltreatment. Ofsted's (2012) recent inspection found evidence of disabled children's views being ascertained by staff that knew them well, with observational techniques being used to interpret the behaviour of children with complex needs. Having reliable access to someone who knows them well and whom they can trust is also important from children's 
perspectives. Receiving a sensitive response from practitioners was highlighted by young people in Cossar et al's (2013) study as critical to establishing a trusting relationship where they could begin to tell about maltreatment.

Analyses of child protection referrals involving disabled children highlight teachers and other school staff as especially important in recognising maltreatment, including that disclosed directly by children themselves. School staff accounted for $36.2 \%$ of substantiated maltreatment in Orelove et al's (2000) survey, and 44\% of referrals in cases examined by Taylor et al (2014). This highlights the need to ensure that all staff members working directly with disabled children have access to awareness training on disabled children's greater risk of maltreatment. Schools also have an important role to play in providing disabled children with the same access as non-disabled children via the curriculum to relationship and sex education, opportunities to discuss healthy relationships and clear information about how to recognise maltreatment and seek help (Cossar et al, 2013). Learning should be tailored to meet disabled children's communication and learning needs and a range of practice resources have been developed for this purpose (see Murray and Osborne, 2009).

Ofsted's (2012) inspection of practice in England identified many cases where emerging concerns for disabled children were identified and dealt with effectively through multi-agency support at an early stage, preventing the need for child protection involvement. Taylor et al's (2014) research also highlighted the need to review services provided to disabled children during and following child protection enquiries to ensure these are appropriate to their needs. Their suggestions include adapting child protection conferences to include disabled children and increasing the number of foster carers able to provide placements for disabled children. Highlighting factors that promote good practice also needs to be reinforced by evidence that these interventions are cost-effective, especially in financially straightened times. However, a recent systematic review identified a lack of research regarding the effectiveness of interventions to prevent and respond to maltreatment involving disabled children (Mikton et al, 2014), and this represents an important direction for future research. One suggestion was that, parenting programmes shown to be effective in preventing child maltreatment could be adapted for families with disabled children and evaluated for effectiveness (Mikton et al, 2014).

\section{Conclusion}

Disabled children have the same rights as all children to be protected from maltreatment. They also have the same rights to express themselves and to have their concerns listened to and appropriately acted upon, to participate fully in decisions made about them and to receive support for themselves to aid recovery 
from maltreatment. Given evidence that disabled children are at greater risk of maltreatment, efforts to recognise and respond to maltreatment concerning them should be afforded greater priority. However, evidence suggests disabled children in the UK generally have poorer access to support and help at all stages of the child protection process.

Accurately recognising maltreatment involving disabled children is admittedly often more complex and time consuming for everyone concerned. However, examples of effective practice, even with children with very complex needs, highlights practitioners' obligation to ensure they have appropriate knowledge and skills to communicate with disabled children about possible maltreatment, rather than relying on disabled children themselves to report it. Practitioners also need to remain alert to changes in disabled children's behaviour that may indicate possible maltreatment. A key recent finding, however, is that disabled children often have a greater capacity to recognise and report maltreatment than is recognised by practitioners (Taylor et al 2014). This underlines the importance of agencies and practitioners ensuring all children have access to regular opportunities to share their concerns, regardless of their additional needs. In addition, disabled children's own perspectives about maltreatment have a crucial part to play in improving child protection practice with this group of children. Although, given what is known about the long-term consequences of maltreatment, it is also imperative that practitioners take heed of effective practice examples by working together and pooling resources to ensure disabled children's rights to protection are upheld.

\section{References}

Ammerman, R.T. (1991) The role of the child in physical abuse: A reappraisal. Violence and Victims, 6, 87-101

Akbas S., Turia A., Karabekirolgu K., Pazvantoglu O., Kekskin T., Boke O. (2009). Characteristics of sexual abuse in a sample of Turkish children with and without mental retardation, referred for legal appraisal of the psychological repercussions. Sexuality and Disability, 27, 205-213

Benedict, M. I., Wulff, L.M. and White, R.B. (1992) Current parental stress in maltreating and non-maltreating families of children with multiple disabilities. Child Abuse and Neglect, 15, 155-63

Blackburn, C., Read, J.M., and Spencer, N. (2010) Prevalence of childhood disability and the characteristics and circumstances of disabled children in the UK: Secondary analysis of the Family Resources Survey. BMC Pediatrics 10, 21

Brandon, M., Sidebotham, P., Ellis. C., Bailey, S., and Belderson, P. (2011) Child and Family Practitioners Understanding of Child Development: Lessons from a small sample of serious case reviews. Research Report DFE-RR110 
Briggs F. (2006) Safety issues in the lives of children with learning disabilities. Social Policy Journal of New Zealand, 29, 43-59

Cicchetti, D., Toth, S. L. and Maughan, A. (2000) An ecological-transactional model of child maltreatment. in A.J. Sameroff, M. Lewis, and S.M Miller (Eds) Handbook of Developmental Psychopathology, Volume 2, 689-722. New York: Kluwer Academic/ Plenum Publishers

Cossar, J., Brandon, M., and Jordan, P. (2011) 'Don't make assumptions' Children and Young People's Views of the Child Protection System. London: Office of the Children's Commissioner

Cossar, J., Brandon, M., Bailey, S., Belderson, P., Biggart, L. and Sharpe, D. (2013) 'It takes a lot to build trust': Recognition and telling: Developing earlier routes to help for children and young people. London: Office of the Children's Commissioner

Connors, C. and Stalker, K. (2003) The Views and Experiences of Disabled Children and Their Siblings: A positive outlook. London: Jessica Kingsley

Connors C. and Stalker, K. (2007) Children's experiences of disability: pointers to a social model of childhood disability. Disability and Society, 22, 1, 19-33

Cooke, P and Standen, P. (2002) Abuse and disabled children: Hidden needs? Child Abuse Review, 11, 1-18

Danseco, E R. (1997) Parental beliefs on childhood disability: Insights on culture, child development and intervention. International Journal of Disability, Development and Education, 44, 41-52

Department of Education (2011) Children in Need Census as at 31 March 2011

Gourdine, R. M. (2013) African-American Children with Disabilities in the Child Welfare System. CW360 The Intersection of Child Welfare and Disability: Focus on Children, Spring 2013, Minnesota: Centre for Advanced Studies in Child Welfare

Herschkowitz, I., Lamb, M.E., Horowitz, D., (2007) Victimisation of children with disabilities. American Journal of Orthopsychiatry, 77, 629-635

Hibbard R.A., and Desch L. W. (2007) Maltreatment of children with disabilities. Pediatrics, $119,5,1018-1025$

Howe, D. (2006) Disabled children, maltreatment and attachment. British Journal of Social Work. 36, 743-760

HM (2011) The Munro Review of Child Protection: Final Report - A child-centred system. London: TSO (CM 8062)

Jaudes P.K, and Mackey-Bilaver L. 2008. Do chronic conditions increase young children's risk of being maltreated? Child Abuse \& Neglect, 32, 671-681

Jemta L., Fugl-Meyer K.S., and Oberg K. (2008) On intimacy, sexual activities and exposure to sexual abuse among children and adolescents with mobility impairments. Acta Paediatrica, 97, 641-646

Jones, L., Bellis, M.A., Wood, S., Hughes, K., McCoy, E., Eckley, L., Bates, G., et al. (2012). Prevalence and risk of violence against children with disabilities: a systematic review and meta-analysis of observational studies. The Lancet, 380(9845), 899-907

Leeb, R.T., Bitsko, R.H., Merrick, R.T., and Armour, B. S. (2012) Does childhood disability increase risk for child abuse and neglect? Journal of Mental Health Research in Intellectual Disabilities, 5, 4-31 
Lightfoot, E.B., Hill K. and La Liberte T.I. (2011) Prevalence of children with disabilities in the child welfare system and out of home placement: An examination of administrative records. Children and Youth Services Review, 33, 2069-2075

Lightfoot, E. B., Hill K. and La Liberte T. I. (2013) Breaking down the silos: Examining the intersection between child welfare and disability. Journal of Public Child Welfare, 7 , $5,471-479$

Kelly, B. (2005). 'Chocolate makes you autism': Impairment, disability and childhood identities. Disability \& Society, 20, 3, 261-275

Kelly, L. (1992) The connections between disability and child abuse: A review of the research evidence. Child Abuse Review, 1, 157-167

Kvam M. H. (2000). Is sexual abuse of children with disabilities disclosed? A retrospective analysis of child disability and the likelihood of sexual abuse among those attending Norwegian hospitals. Child Abuse \& Neglect 24, 1073-1084

Kvam, M. H., (2004) Sexual abuse of deaf children. A retrospective analysis of the prevalence and characteristics of childhood sexual abuse in deaf adults in Norway. Child Abuse and Neglect, 28, 241-251

MacKenzie, M.J., Kotch, J. B. and Lee, L. (2011) Toward a cumulative ecological risk model for the etiology of child maltreatment. Child and Youth Services Review, 33, 1638-1647

Manders, J. E., and Stoneman, Z., (2009) Children with disabilities in the child protective services system: An analog study of investigation and case management. Child Abuse and Neglect, 33, 229-237

Mikton, C., Maguire, H., and Shakespeare, T. (2014) A systematic review of the effectiveness of interventions to prevent and respond to violence against persons with disabilities. Journal of Interpersonal Violence, 29, 17 3207-3226

Murray, M. and Osborne C. (2009) Safeguarding Disabled Children: Practice guidance. London: DCSF

NSPCC (2003) It Doesn't Happen to Disabled Children. Child protection and disabled children. Report of the National Working Group on Child Protection and Disability

Ofsted (2012) Protecting disabled children: thematic inspection [http://www.ofsted.gov.uk]

Orelove, F.P., Hollahan, D.J., and Myles, K.T (2000) Maltreatment of children with disabilities: Training needs for a collaborative response. Child Abuse and Neglect, 24, 185-194

Osborne, C. (2013) How the latest research on safeguarding disabled children should inform social work. Community Care 24/02/13, [http://www.communitycare.co.uk/2013/02/24/ how-the-latest-research-on-safeguarding-disabled-children-should-inform-socialwork/]

Raghavendra, P., Olsson, C., Sampson, J., McInerney, R., and Connell T. (2012) School participation and social networks of children with complex communication needs, Physical disabilities and typically developing peers. Augmentative and Alternative Communication, 28, 1, 33-43

Reading, R., Bissell, S., Goldhagen, J., Harwin, J., Masson, J., Moynihan, S., Parton, N., Santos Pais, M., Thoburn, J., and Webb, E. (2009) Promotion of childrens rights and prevention of child maltreatment. The Lancet, 373, 332-343

Sidebotham, P., Heron, J. and Golding, J. (2002) Child maltreatment in the 'children in the 
nineties': Deprivation, class and social networks in a UK sample. Child Abuse and Neglect, 26 (2), 1243-1259

Sobsey, D. (1994) Violence and Abuse in the Lives of People with Disabilities: The end of silent acceptance? Baltimore: Paul Brookes

Spencer, N., Devereux, E., Wallace, A., Ratna, S., Manjula, S., Bacchus, C., and Logan, S. (2005) Disabling conditions and registration for child abuse and neglect: A population-based Study. Pediatrics, 116, 3, 609-613

Stalker, K., (2012) Researching the lives of disabled children and young people. Children $\&$ Society, 2012, 26, 3, 173-180

Stalker, K., Lister-Green, P., Lerpiniere, J., McArthur, K. (2010) Child Protection and the Needs and Rights of Disabled Children: Abridged report. Glasgow: University of Strathclyde / Sir Halley Stewart Trust

Stalker, K. and McArthur, K. (2012) Child abuse, child protection and disabled children: A review of recent research. Child Abuse Review, 21, 1, 24-40

Stith, S.M., Liu, T., Davies, C., Boykin, E.L., Alder, M.C., and Harris, J.M. (2009) Risk factors in child maltreatment: A meta-analytic review of the literature. Aggression and Violent Behavior, 14, 13-29

Sullivan, P. and Knutson, J. (2000) Maltreatment and disabilities: A population based epidemiological study. Child Abuse \& Neglect, 24, 125-1273

Taylor, J., Stalker, K., Fry, D. and Stewart, A.B.R. (2014) Disabled Children and Child Protection in Scotland: An investigation into the relationship between professional practice, child protection and disability. [www.scotland.gov.uk/Publications/2014/04/4363/13]

Thoburn, J. (2013) Services for vulnerable and maltreated children. in I. Wolfe and M. McKee (Eds) (2013) Children's Health Services and Systems: A European perspecitve. Milton Keynes: Open University Press

United Nations (1989) Convention on the Rights of the Child. (UNCRC). Geneva: UNICEF

UN Committee on the Rights of the Child (2003). General comment number 5: general measures of implementation of the convention on the rights of the child. CRC/GC/2003/5. Geneva: Office of the UN High Commissioner for Human Rights [http:/www.ohchr.org/ English/bodies/crc/docs/GC5_en.doc]

United Nations (2006) Convention on the Rights of Persons with Disabilities. (UNCRPD), Geneva [http://www.un.org/disabilities]

van IJzendoorn, M., Goldberg, S., Kroonenberg, P.M. and Frenkel, O. (1992) The relative effects of maternal and child problems on the quality of attachment: A meta-analysis of attachment in clinical samples. Child Development, 63, 840-58

Verdugo, M.A., Bermejo, B.G. and Fuertes, J. (1995) The maltreatment of intellectually handicapped children and adolescents. Child Abuse and Neglect, 19, 205-15

Watson, N., Davis, J., Shakespeare, T., Barnes C., Priestley, M., and Cunningham-Burley, S. (2000) Life as a Disabled Child: A qualitative study of young people's experiences and perspectives. Leeds: Disability Research Unit, University of Leeds

Watson, N. (2012) Theorising the lives of disabled children: How can disability theory help? Children and Society, 26, 192-202 
Westcott, H.L. and Jones, D.P.H. (1999) Annotation: The abuse of disabled children. Journal of Child Psychology and Psychiatry and Allied Disciplines, 40, 4, 497-506

Wickenden, M. (2011) 'Talk to me as a teenager': Experiences of friendship for disabled teenagers who have little or no speech. Childhoods Today, 5 1, 1-35

Ytterhus, B. (2012) Everyday segregation amongst disabled children and their peers: A qualitative longitudinal study in Norway. Children \& Society, 26, 203-213 